\title{
Ni con Lima ni con Madrid. Guerrillas rurales en la guerra de Independencia del Perú
}

\section{Neither with Lima nor with Madrid. Rural guerrillas in the war of independence of Peru}

Silvia Escanilla Huerta ${ }^{1}$

\section{Resumen}

La historiografía sobre la independencia en el Perú ha estado centrada en determinar si el "pueblo" peruano fue o no protagonista de la guerra y si quiso o no separarse políticamente de la corona española. A pesar de los esfuerzos recientes por trascender posturas dicotómicas, aún escasean los trabajos que analizan por qué la gente decidió participar de la guerra, más allá del bando que eligiera para hacerlo. Este artículo intenta responder esa pregunta analizando los antecedentes de la movilización que precedió a la guerra, así como las características de la organización de guerrillas en el espacio rural peruano durante la misma. La propuesta es analizar la experiencia de la guerra en el nivel local para proponer a las guerrillas como una forma particular de participación política popular, que fue decisiva en la guerra porque puso de manifiesto la emergencia de poderes autónomos en el nivel local y regional.

$1 \mathrm{PhD}$. Candidate, University of Illinois at Urbana-Champaign.

Correspondencia (Corresponding author): escanil2@illinois.edu; Código ORCID: 0000-0001-7196-9490 
Palabras clave: Guerra de independencia, guerrillas, plebeyos, Constitución de Cádiz, rebeliones indígenas

\section{Abstract}

Traditionally, the historiography of the independence of Peru has focused on the peoples' desire (or lack thereof) of breaking free from the Spanish crown. Despite recent efforts to transcend dichotomous interpretations, there are still few studies that analyze why the people decided to participate in the war, regardless of the side they took. This article explores their motivation for participating in the war by analyzing the background of the social mobilization prior to the war, as well as the characteristics of guerrilla organization in rural Peru during the war of independence. By focusing on how people lived and experienced the war, this article demonstrates that guerrillas constituted a specific form of popular political participation, which were decisive in the definition of the war because they represented the emergence of autonomous local and regional powers within the vice regal space.

Keywords: Independence war, guerrillas, Constitution of Cadiz, plebeians, indigenous rebellions

\section{Introducción}

160 En septiembre de 1820, el Ejército Libertador desembarcó en las costas del virreinato del Perú con un objetivo: lograr la independencia de la región. Su llegada produjo un quiebre en la situación militar del virreinato porque a partir de ese momento se abrió un nuevo frente de guerra, sumado al que existía en el Alto Perú. Era la primera vez que el ejército realista se hallaba en una posición de defensa. Luego del desembarco, San Martín lanzó varias proclamas a los pueblos del virreinato, en las que los invitaba a sumarse a su causa 
(Paz Soldán, 1868, p. 66). Un mes después del desembarco, partió una expedición a la sierra dirigida por el general Juan Antonio Álvarez de Arenales con el objetivo de lograr el apoyo efectivo de los habitantes al Ejército Libertador, ya fuera con hombres o víveres. ${ }^{2}$ Durante esa expedición, Álvarez de Arenales se ocupó de organizar partidas de guerrillas integradas por los pobladores locales para que cumplieran labores de apoyo logístico, y de asedio y hostigamiento al ejército real debido a su mejor conocimiento del terreno y de los recursos que en él hubieran. ${ }^{3}$

La organización de esas guerrillas ha permitido a algunos historiadores afirmar que el pueblo peruano luchó por su independencia. Sin embargo, otros historiadores no dudaron en afirmar que "los peruanos no habían optado por ser independientes" (Anna, 2003, p. 253) y que no realizaron "una contribución decisiva" (Lynch, 1980, p. 183) a la causa independentista. ${ }^{4}$ Este debate se enmarcó en una polémica más amplia que dividió a la historiografía peruana del siglo XX. En efecto, la historiografía sobre la independencia en el

2 Las principales ciudades fueron Huancavelica, Huamanga, Huanta, Huancayo, Cerro de Pasco, Tarma y Huaura.

3 “(...) debo decirle que por pretexto alguno comprometa una acción formal con los enemigos y solo debe vuestra señoría ceñirse a una guerra de recursos (...) partidas cortas, la que más de cien hombres mandadas por patriotas de alguna inteligencia y con conocimientos del terreno donde hacen la guerra; hostilizando al enemigo con preferencia por sus costados y retaguardia, deben hacerlo sucumbir en el término de dos meses..." carta de San Martín a Francisco de Paula Otero, gobernador intendente de la provincia de Tarma, 04/01/1821 (Comisión Nacional del Sesquicentenario de la Independencia del Perú, Colección Documental de la Independencia del Perú (en adelante CDIP) (CDIP, 1971, t. V, vol. 1, p. 187).

4 Entre quienes consideraron que las guerrillas fueron una expresión del patriotismo de los peruanos se encuentran Rivera Serna (1958), Vergara (1973), Beltrán Gallardo (1977) y Roel Pineda (1988). 
Perú de las últimas décadas ha estado centrada en determinar si el "pueblo" peruano fue o no protagonista de la guerra y si quiso o no separarse políticamente de la corona española. La polémica se inició con la contribución de Heraclio Bonilla y Karen Spalding (1972), quienes en un célebre trabajo plantearon que "el hecho fundamental es este gran silencio de las masas populares del Perú: su no participación en el proceso de la independencia..." (p. 43). En un trabajo posterior, Bonilla sostuvo que si bien los sectores plebeyos participaron en la guerra a través de la conformación de guerrillas y montoneras, la oposición de los pueblos a la causa de la independencia había sido mucho más importante de lo que la historiografía tradicional había manifestado (Bonilla, 2007, p. 69) No está en las referencias bibliográficas; hay de 1972 .

En los últimos años han existido numerosos intentos de superar esta dicotomía, pero pocos estudios han analizado en profundidad la actividad guerrillera para comprender los móviles de la participación plebeya en ellas. ${ }^{5}$ El objetivo del presente artículo es hacer una contribución en ese sentido, plantear nuevos interrogantes sobre la participación plebeya en la guerra de Independencia y ofrecer posibles respuestas. ${ }^{6}$

\section{Los antecedentes de la movilización}

Una de las primeras preguntas que surgen cuando se piensa en un escenario bélico es por qué la gente decide participar de la guerra, más allá del bando qué elija para hacerlo. En 162 este caso, ¿qué razones pudieron haber tenido para exponer sus vidas en el proceso? ¿Por qué prefirieron sumarse a un

5 Los estudios son en su mayoría análisis de casos locales. Véanse Cáceres Olazo-Monroy (1999), Igue Tamaki (2008), Sánchez Jara (2010), Mendoza Villanueva (2012), Adanaqué Velásquez (2012), Rosado Loarte (2017).

6 Una definición de lo plebeyo en Di Meglio (2006). 
ejército que venía a invadirlos? ¿Por qué eligieron sumarse al ejército realista?

Una posible explicación la encontramos en la situación política del virreinato en las décadas previas a la guerra de Independencia. Durante todo el siglo XVIII, el virreinato del Perú fue conmovido por varias rebeliones de distinta índole y diversa intensidad (O'Phelan Godoy, 1988, p. 289). Aunque algunos autores han señalado que la rebelión de Túpac Amaru clausuró una era de rebeliones, el siglo XIX no estuvo exento de ellas (O’Phelan, 1987; Serulnikov, 2006 y 2010). Varios estudios muestran que la movilización política, especialmente de los sectores indígenas no se detuvo con la represión de la rebelión tupamarista, sino que continuó y se entrelazó con los reclamos de diversos actores del mundo rural y urbano en particular en el sur del virreinato (Cahill, 1988 No está en las referencias bibliográficas; Cahill y O'Phelan Godoy, 1992; Fisher, 2000; Seiner, 2001; O’Phelan Godoy, 2009; Klassen, 2016; Bazán Díaz, 2017). Ese panorama dinámico de numerosos focos de conflicto en los primeros veinte ańos del siglo revela que existía un descontento social y político con anterioridad a la llegada del Ejército Libertador. Además del fracaso de las rebeliones, debido en la mayoría de los casos a desinteligencias y mutua desconfianza al interior de los grupos rebeldes, se puede alegar que hubo intentos concretos por desafiar el poder de la corona española en el virreinato del Perú en ese periodo.

Por otra parte, luego de la revolución de Cuzco de 18141815, varios historiadores coinciden en afirmar que hubo continuidad en la actividad insurgente, a pesar de los numerosos intentos del gobierno virreinal en Lima por sofocar y eliminar los focos rebeldes (Demélas, 2007; Soux, 2010; Mamani Siñani, 2010). Desde ese punto de vista, la idea de un virreinato del Perú contrarrevolucionario debe necesariamente convivir con la idea de un Perú igualmente revolucio- 
nario. Más allá de lo efímero de la resistencia, es indudable que existía un sentimiento de abierta oposición al gobierno espańol, que indica a su vez un agotamiento de las relaciones entre la Corona y ciertos actores sociales del virreinato.

Asimismo, se debe tener en cuenta los cambios políticos introducidos por las reformas borbónicas, los que fueron reforzados con posterioridad a la rebelión de Túpac Amaru. Los efectos de esas reformas en las comunidades indígenas no pueden ser ignorados debido a que a la pérdida de poder de las élites indígenas en el interior de sus comunidades se le sumó la intromisión de funcionarios ajenos a las comunidades en aspectos tan sensibles como la recaudación del tributo o la administración del poder, de justicia y policía (Sala i Vila, 1996; Garrett, 2009). En ese contexto, se inició una reconfiguración de constelaciones de poderes locales en los que los cabildos de indios ganaron protagonismo a expensas de las antiguas familias curacales y funcionaron en oposición a las redes de poder oficiales, de las cuales los curacas habían formado parte (Maqque, 2015). La difusión de las ideas provenientes de la revolución de Buenos Aires encontró en esas nuevas élites un terreno fértil donde germinar, lo cual explica la supervivencia de la actividad guerrillera aun cuando los ejércitos porteños ya se habían retirado del Alto Perú.

Un tercer aspecto del panorama político de esas primeras décadas es el fenómeno del bandolerismo. Desde fines del siglo XVIII y en especial durante las primeras décadas del siglo XIX existió una intensa actividad delictiva, constituida por bandas de salteadores que recorrían libremente los caminos de la costa y se dedicaban a asaltar a los transeúntes y las haciendas de la zona. Flores Galindo (1984) señaló que esos grupos de salteadores eran esencialmente reformistas, por cuanto no buscaban cambiar el sistema ni amenazar al dominio español en el Perú, sino tan solo lograr un mejor reparto de los beneficios del sistema (p. 147). Sin embargo, eran una 
expresión del malestar que experimentaba la sociedad colonial y constituían un abierto desafío a la autoridad colonial. Los oficiales de la corona lo reconocían abiertamente al admitir que no podían controlarlos con los recursos que tenían:

... nuestras fuerzas reunidas en la capital y sus inmediaciones no pueden reducirse a pequeñas partidas porque no hay numero que alcance ha atender a distancias que parece no tuvieran fin, cuanto por su terreno es grandes arenales, falta de viveres y en algunas partes su poblacion y aguadas...

Los recursos con los que contaba el ejército realista y la forma en que estas bandas operaban no le permitía mantenerlas bajo control. Esas bandas estaban formadas por indígenas, mestizos pobres y negros en la mayoría de los casos, es decir, eran socialmente heterogéneas y solían incluir además de hombres libres a esclavos. Según Christine Hünefeldt (1979), el bandolerismo constituyó una vía de escape para los esclavos coloniales, porque les permitía probar la libertad y la posibilidad de vivir al margen de las estrictas categorías sociales. Los palenques que existían por toda la costa eran refugios para los bandoleros, pero también para los esclavos fugados de haciendas o de la ciudad. Todos se las arreglaban para ir y venir por la zona manteniendo una vida clandestina y peligrosa, pero también para constituir "una fuerza consistente y peligrosamente autónoma” (p. 82).

Por otra parte, José Luis Igue Tamaki (2008) detectó la existencia de bandolerismo en la sierra de Ayacucho, en ese caso, relacionado fundamentalmente con el robo de ganado, aunque con modalidades diferentes dependiendo de la zona y la forma de tenencia de la tierra. Igue Tamaki demuestra que el bandolerismo no era un hecho únicamente atribuible a

7 AGN Lima, sección colonial. Superior Gobierno, leg. 37, C. 1324, 1821. 
la costa ni era una actividad en la que predominaran los esclavos y libertos negros (p. 33). Si bien es necesario contar con más estudios de caso para calcular la real dimensión del fenómeno, resulta sugestiva su proliferación en sitios tan diferentes, como Cañete y Cangallo, lo que hace suponer que su extensión debió ser aún mayor.

Ese panorama de pequeñas bandas armadas que asolaban los caminos de la costa y de la sierra sumada a la de las guerrillas del Alto Perú muestra que si bien no hubo una amenaza directa al dominio español en los años previos a la guerra de Independencia, sí existió un desafío a su autoridad. Siguiendo a Christine Hünefeldt (1982), después de la revolución del Cuzco en 1815 los funcionaros coloniales se mantuvieron atentos a evitar cualquier atisbo de descontento en el interior del virreinato. Si bien la revolución fue aplastada, el temor a nuevos estallidos como los ocurridos en Chile, Quito y Buenos Aires motivó que los funcionarios reales no ejercieran excesiva presión tributaria (pp. 186-187). Esa actitud significó en cierto modo una victoria para los pueblos rurales y comunidades de indios porque a pesar de que el gobierno virreinal estaba necesitado más que nunca de ingresos para sustentar la guerra en el Alto Perú, si los indígenas se negaban a pagar el tributo no había quien pudiera detenerlos. Por ello, la actitud tomada por el gobierno virreinal no hacía más que evidenciar la debilidad de su estructura de poder, la que se haría patente a partir del desembarco del Ejército Libertador en 1820 .

\section{La dimensión política de la participación plebeya}

En 1820, la actividad de guerrilleros y bandoleros se multiplicó en todo el territorio virreinal fustigada por el desembarco del ejército de José de San Martin y la red de propaganda y rumores que sus aliados se encargaron de esparcir. Por ello, es posible afirmar que a partir de ese momento la actividad 
bandolera-guerrillera dejó de ser reformista y adquirió una importancia política definida por la necesidad que tenían ambos ejércitos de contar con hombres dispuestos a ir a la guerra. Igue Tamaki (2008, p. 34) señala que algunos bandoleros también fueron acusados del delito de infidencia, con lo cual sus actividades dejaron de constituir simples delitos y adquirieron cierta dimensión política. Esa dimensión política se acentuó con el transcurso de la guerra, como lo manifestaban las propias autoridades virreinales:

... es notorio que cada dia se van aumentando, mas que aseguran que tambien en la quebrada de Caballero hay una partida de diez, los mas con armas de fuego; siendo tambien sensible que los esclavos y libres de color se estan preparando a sublevarse con noticia que tienen de los que se han pasado al partido del enemigo en la carrera de cañete y chincha. ${ }^{8}$

Flores Galindo (1984), Walker (1990) y Guardino (1989) han coincidido en afirmar que el bandolerismo adquirió contenido político durante la guerra de Independencia. Su gravitación política estuvo dada por el hecho de que esas bandas armadas apoyaron a uno y otro bando, dado su conocimiento del terreno y su acceso a los víveres necesarios para sostener económicamente a los ejércitos. ${ }^{9}$ Esos grupos armados utilizaron su lealtad durante la guerra como arma de negociación para la obtención de ciertos derechos durante la nueva etapa. Al hacerlo, afirmaron una identidad local propia que modificó efectivamente las relaciones entre el gobierno y la

8 AGN Lima, sección colonial, Real Audiencia Lima, causas criminales, leg. 37 C. 1332, 1820. Oficio elevado por Don Pablo José Alvarado, hacendado del valle de Carabayllo, al mariscal de los ejércitos de S.M., Conde de Valle Oselle, Marqués de Montemira, solicitando patrullas para batir a los malhechores que pululan el valle de Carabayllo, en especial en la quebrada de Caballero.

9 La referencia más clara es la guerrilla de Ninavilca y también la de los morochucos de Cangallo. 
sociedad respecto de la etapa anterior. Un ejemplo claro es la identidad morochuca, creada a partir de su participación en la guerra y utilizada para negociar los términos de su obediencia al nuevo Estado (Igue Tamaki, 2008, p. 38; Walker, 2004, p. 117).

Desde ese punto de vista, es posible afirmar que en ese clima de descontento social y político, la llegada del Ejército Libertador fue percibida por distintos grupos sociales como una oportunidad para asociar intereses y reclamos particulares a los de un ejército poderoso, pero necesitado de hombres y recursos materiales. Ese fue el caso de los esclavos negros que se sumaron al Ejército Libertador a cambio de la manumisión. Christine Hünefeldt (1979, p. 82) señala que muchos vieron la opción de unirse al Ejército Libertador como una oportunidad de escapar de sus amos y probar el sabor de la libertad, aunque para ello tuvieran que ir a la guerra. Asimismo, la persistencia durante varios años de dos autoridades políticas diferentes permitió que no pocos hombres desertaran y se dedicaran a subsistir sin responder a autoridad alguna.

En otros casos, la defensa de los intereses económicos más inmediatos tuvo mucho que ver con la adhesión a uno u otro bando. Tal fue el caso de Tomas Gomes, arriero de mulas quien se dirigía al Marqués de Vallehumbroso en octubre de 1820 para señalarle que:

He meditado ser de primera necesidad la conservación de la Quebrada de Lunaguaná para sostener la correspondencia con el Alto Perú y Arequipa que tan interesante nos es, luego que empiecen las ostilidades an de tratar de cortar toda comunicacion y siendo esta la unica que nos queda consulto a V.S. este negocio con el objeto que se me destine a cubrir aquel punto quando sea tiempo en razon de que con la infanteria tan corto numero no podre / operar en otro punto que el de un estrecho por medio de una emboscada: el de la quebrada de Lunaguaná es un estrecho... desde el ańo cinco que estoy en este partido y con el motivo del cobro 
de mis negociaciones de mulas he tomado bastante conocimiento del terreno. De la seguridad de este punto resulta la de mantener mi Partido en quietud, la correspondencia expedita aunque Cañete llegase a ser del enemigo, en cuyo caso yo formaria un derrotero para su direccion, el de que no se hagan de los indios de Lunaguaná y Pacarán ni de algunas propiedades de algunos vecinos. Todo lo pongo en consideracion de V.S. ${ }^{10}$

Aquí se pone de manifiesto que a este arriero le preocupaban sobre todo la seguridad de su pueblo y de sus negocios. Por ese motivo, se ofrecía a llevar la correspondencia cuando comenzaran las hostilidades, a cambio de que se protegiera el único camino posible de ser transitado luego de que el Ejército Libertador controlase la zona. Asimismo, vale notar cómo alertó a las autoridades sobre la frágil lealtad de los indígenas, que desde su perspectiva podían volverse en contra del gobierno virreinal. Con el mismo criterio, pero con resultados diferentes José Gavañas informaba al intendente Gárate en noviembre de 1820 sobre la poca colaboración de los pueblos para el abastecimiento del ejército realista:

... me han avisado de Zepita, despues de haberlo registrado todo no ha reunido ni un solo quintal de cebada en rama ni una fanega en grano, con que este pueblo no hay que esperar... que cebada en grano nada, aunque ocurrio a Copacabana no encontro ni con suplica. ${ }^{11}$

Esa falta de colaboración era motivada en muchos casos por la reiteración en las exacciones que terminaba por agotar a las poblaciones, a lo que se sumaba muchas veces la violencia con la que eran demandadas. Del lado del Ejército Libertador, la situación no era diferente. Aquellos que brindaban su adhe-

10 Nota de Tomás Gomes al Marqués de Vallehumbroso. Recomienda medidas para la conservación de Lunaguaná (CDIP, t. V, v. 1, doc. 32, p. 69).

11 Oficio de José Gavañas a Tadeo Gárate, Chucuito, 11/11/1820 (CDIP, t. V, v. 1, doc. 40, p. 83). 
sión al ejército de San Martín también lo hacían siguiendo en muchos casos un interés propio. Francisco de Paula Otero, gobernador intendente de la provincia de Tarma, señala en una nota de diciembre de 1820 que:

... esos tenientes gobernadores solo quieren mantener sus partidos y asi nos comeran pueblo por pueblo. No permita U. que esos vecinos tengan armas y para evitarlo publique bandos de que las entreguen. Aciendo esto comprensivo a los Pueblos de ese contorno para que presenten los fuciles que Aigan recojido... ${ }^{12}$

Paula Otero era consciente de lo frágil de la adhesión de los pueblos, los que solo se organizaban militarmente para defender sus territorios y no, como pretendía este, para ponerse a las órdenes del Ejército Libertador. A pesar de ello, no podían no contar con ellos para llevar adelante la guerra, tal como indica este comunicado:

En este momento acabo de recibir noticia cierta de que el enemigo esta en Iscuchaca con toda su fuerza, a donde llego ayer mañana, ordenando a uno de los del pueblo de Acostambo que le aprontase o tuviese listas 50 cargas de cebada, igual numero de vacas y correspondientes carneros para su tropa. Este, paso de largo a darme aviso y tras este vienen varios con la misma noticia... acabo de ordenar que todas las comunidades vayan a tomar los cerros de Naquinpuquio o Huaznapuquio con sus ondas y demas armas que tengan... ${ }^{13}$

Los generales del Ejército Libertador necesitaban la colaboración de los lugareños para tener una posibilidad de derrotar al ejército realista. Dependían de la información que estos les proveían y de que las comunidades indígenas les prestaran apoyo logístico y militar. A su vez, esos pueblos eligieron transmitir las noticias al ejército invasor para evitar la

12 Nota de Francisco de Paula Otero, Tarma, 17/12/1820 (CDIP, tomo V, v. 1, doc. 114, g. 149).

13 Comunicación de Marcelo Granados al Teniente Gobernador De Paula Otero, diciembre de 1820 (CDIP, t. V, v. 1, doc.132, g. 164). 
exacción de que iban a ser objeto. Al informarles sobre los movimientos del ejército realista, evadieron la entrega de los víveres solicitados por este, aun cuando más tarde tuvieran que entregar esos mismos víveres al Ejército Libertador. No solo ganaban tiempo con la infidencia, sino que mantenían sus posesiones a salvo, al menos por el momento.

Se podría argumentar que ese tipo de racionalidad era poco frecuente y que no constituiría un patrón común. Sin embargo, las fuentes muestran una y otra vez que ante una situación que podía poner en entredicho su lealtad, los pueblos y comunidades elegían a quién entregársela teniendo en cuenta móviles que no pocas veces eran ajenos a la cuestión de la independencia. Lo ocurrido en el pueblo de Caquingorá es un buen ejemplo de ello. El episodio del robo de tributos a un recaudador por parte de una partida patriota mientras este se hallaba de paso por el pueblo adquiere otra dimensión cuando el expediente criminal revela el papel que tuvieron algunos pobladores en el hecho. El citado recaudador de tributos del pueblo de Curaguara para el gobierno realista declaró que:

... por precauciones que oportunamente tome, con noticias del desembarco de los insurgentes.... me dirigí a Caquiavire, capital del partido, en donde se hallaba el subdelegado y para mejor tome la dirección de Caquingora, persuadido estar mas seguro pero con fatalidad que a las seis horas de llegado al pueblo ese, o ya sea que por aviso anterior que hayan tenido de mi arribo o porque la casualidad lo permitiese, tuve la desgracia de ser sorprehendido por un sargento insurgente ... como el expresado dinero por mejor había ocultado en la iglesia aun antes de tener noticia de los enemigos negué abiertamente que lo tenía, mas en bano fue mi tenacidad porque de estudio habían estado en sus cimuladas inquisiciones quando ya el dinero lo habían extraído del lugar donde lo oculte. ${ }^{14}$

14 AGN Lima, sección colonial, Superior Gobierno-Contencioso (GO BI 5) legajo 189, C. 1190, 24 fs., 1823-1824. 
Las autoridades realistas dudaron de la inocencia del recaudador y por ello promovieron el expediente, aunque nunca se llegó a esclarecer el hecho. Sin embargo, en ningún momento cuestionaron la actuación del pueblo mismo, aunque resulta evidente que en el pueblo sabían que la partida patriota estaba cerca de la zona, dada la poca distancia entre la base patriota y Caquingorá y los propios dichos del recaudador. Resulta llamativo que nadie le haya advertido al recaudador, o mejor, hubo quienes le advirtieron y por eso este guardó el dinero en la iglesia, así como también hubo quienes avisaron al Ejército Libertador para que buscaran el dinero allí mismo antes de apresar al recaudador. De aquí se desprende que los pueblos solían ver pasar a partidarios de los dos bandos y no había un comportamiento monolítico frente a cada agente. Algunos tomaban partido por los realistas y otros por los patriotas. Pero, ¿¿de qué dependía esto? Es razonable la idea de que prefirieran ayudar a los patriotas en lugar del recaudador, dado el tradicional encono que los pueblos sentían por quienes no formaban parte de la comunidad y se apropiaban de los frutos de su trabajo en nombre del rey. Asimismo, si bien el recaudador pudo haber sido alertado de la presencia de partidas patriotas en la zona, resulta razonable suponer que nadie lo ayudó cuando hubo de enfrentarse a ellos, ni siquiera el cura de la iglesia, pues el recaudador no menciona nada por el estilo en su declaración. Los vecinos tuvieron bastante tiempo como para saber que el recaudador estaba en el pueblo (porque menciona haber permanecido seis horas allí antes de que lo apresaran) y también para saber que la partida patriota venía a buscarlo. Si no hicieron nada o si les facilitaron el trabajo a los patriotas, no parece que lo hicieran tanto porque ellos mismos fuesen patriotas, como porque les daba lo mismo lo que ocurriera y en todo caso era preferible que le robaran al recaudador a que les pidieran una contribución a ellos. Una conclusión aceptable sería deducir que los vecinos del pueblo de Caquingorá actuaron como mejor convenía a sus intereses, los cuales, en el contexto de una 
guerra prolongada y gravosa, siempre serían los de perjudicar a otro que no fueran ellos mismos.

Con respecto a este último punto, es posible que esos individuos no hicieran análisis tan racionales del contexto o de las acciones que llevaban adelante. Sin embargo, la historiografía más reciente ha dado numerosas pruebas de ese tipo de racionalidad en los sectores plebeyos, no solo entre los que apoyaban a los patriotas, sino también entre los que eligieron adherirse a los realistas (Fradkin, 2006; Di Meglio, 2006; Mata, 2008; León, 2011; Echeverri, 2016). Asimismo, si bien se ha planteado una asociación entre etnicidad y adhesión a uno u otro bando, las fuentes revisadas no revelan evidencias contundentes al respecto. ${ }^{15}$ Lo que se observa es que todos los que integraban los sectores plebeyos en la sociedad virreinal (negros esclavos o no, mestizos e indígenas) actuando solos o en conjunto eligieron a qué bando apoyar dependiendo de las circunstancias. Es muy posible que lo que motivara a los pueblos a optar por un bando u otro estuviera intrínsecamente relacionado con la defensa de sus intereses más inmediatos, es decir, con sus propiedades, su ganado y sus cosechas.

\section{La militarización de la sociedad}

El siglo XVIII en el virreinato del Perú tuvo rebeliones indígenas de distinta envergadura, pero esa situación no implicó que hubiera una presencia permanente del ejército en la vida cotidiana de la sociedad virreinal (O’Phelan Godoy, 1988). Si bien existía un alto nivel de conflicto social, esa sociedad solía resolver sus disputas a través de la vía judicial. Aunque durante el siglo XVIII se produjo un cambio, dado que los sectores

15 Según O’Phelan Godoy (2011, p. 425) serían los “cholos”, quienes estarían más inclinados a cambiar de bando porque no contaban con la protección de las comunidades indígenas y eso les daba más libertad de acción. 
indígenas alternaron la vía judicial con asonadas y rebeliones (Serulnikov, 2006), no se puede afirmar que la sociedad virreinal peruana fuera una sociedad militarizada (Hünefeldt, 1982, pp. 187-190; Lévano, 2011 No está en las referencias bibliográficas; Sánchez, 2011). El peso numérico de las milicias era escaso con respecto a la población y eran vecinos que contaban con muy poca o ninguna instrucción militar (Ragas, 2004 No está en las referencias bibliográficas). Los cambios introducidos en el fuero militar por los Borbones a mediados del siglo XVIII tuvieron en el Perú un alcance diferenciado como consecuencia del impacto de la rebelión de Túpac Amaru. En el sur, debido a las numerosas rebeliones, la formación de milicias fue muy limitada y se prefirió destacar regimientos formados en su mayoría por peninsulares, a los que se sumaban levas masivas de indígenas cuando el caso lo requería (Sánchez, 2011). En el norte, en cambio, se formaron cuerpos de milicias en los que los jefes milicianos lograron desarrollar redes de poder locales. Cuando se produjo el desembarco del Ejército Libertador, San Martin logró establecer una fluida comunicación con el intendente Torre Tagle, quien disponía de "competentes fuerzas de milicias perfectamente arregladas y disciplinadas, al mando de jefes y oficiales criollos (como se decía entonces) y de su completa confianza" (Rebaza, 1989, p. 13). Resulta evidente que esas milicias habían adquirido una gravitación política que sería clave para optar por apoyar el proyecto político sanmartiniano. A pesar de ello, no se puede decir que la alianza entre la élite trujillana y el Ejército Libertador sumara automáticamente a toda la intendencia. De hecho, las ciudades y pueblos de la región se fueron plegando a la propuesta patriota, pero lo hicieron consensuando entre los vecinos de cada pueblo la forma más eficaz de actuar de acuerdo con sus intereses (p. 48).

En el caso puntual de Piura, los historiadores han demostrado eficazmente cómo la élite piurana se adaptó a la independencia al modificar su conducta hacia los patriotas en función de sus intereses económicos y políticos (Aldana, 
1997; Hernández García, 2008, p. 384). En ese sentido, no siempre sus intereses coincidieron con los intereses de los sectores plebeyos. Por ejemplo, en el caso de Paita en 1819 las comunidades indígenas recibieron a la escuadra de Lord Cochrane con los brazos abiertos a pesar de los deseos de la élite que todavía apoyaba al ejército realista y temía no poder controlarlos (p. 282). En el caso de Supe y Huaura, si bien alojaron al grueso de las tropas libertadoras, la adhesión al Ejército Libertador tuvo sus matices. Los recelos y desconfianzas mutuas entre poblados llevaron a que las milicias de Supe, Barranca y Pativilca solicitaran formar un regimiento separado del de Huaura, en caso contrario la disciplina y obediencia de estos se vería comprometida. ${ }^{16}$ Asimismo, no se podía contar con ellos de forma permanente, ya que al ser en su mayoría campesinos, estaban sujetos a las épocas de siembra y cosecha, momentos en los que abandonaban las responsabilidades bélicas (Sánchez Jara, 2010, p. 81).

En otros casos, sectores urbanos y rurales coincidieron en apoyar a un ejército. Ese fue el caso de la ciudad de Huánuco en su pronunciamiento a favor del Ejército Libertador en 1822. ${ }^{17}$ Los lideres del Ejército Libertador convocaron a "juntas populares", donde informaban a los vecinos que se les proveería de armas y municiones para la defensa de la ciudad. Asimismo, ellos podían elegir a sus comandantes, un dato muy valioso a la hora de comprender el apoyo a una $\mathrm{u}$ otra causa. El Ejército Libertador a priori no se les imponía, no los subordinaba ni les proponía otra cosa que "defender la ciudad". El documento, si bien exalta el patriotismo de los huanuqueños, permite comprender que más que adherir a la independencia, la gente estaba ansiosa por defender su

16 Memorial de los vecinos de Supe, Barranca y Pativilca solicitando la formación de un regimiento, 4/4/1823 (CDIP, t. V, v. 4, p. 227).

17 Oficio de Mariano Sánchez a José de Rivadeneyra y Tejada, Huánuco, 3/01/1822 (CDIP, t. V, v. 2, doc. 517, pp. 11-13). 
territorio. De hecho, el documento señala que los indígenas ya se habían sumado a los patriotas pues "tenian ya coronadas las cumbres de las montañas para hostilisar al enemigo en los desfiladeros por donde habia de pasar". Los vecinos de la ciudad sumados a los indígenas formaron grupos de montoneras que esperaron a los realistas en las afueras de la ciudad. Toda la organización y gasto de la empresa corrió por cuenta de la ciudad y algunos vecinos hicieron contribuciones destacadas, incluidos algunos vecinos peninsulares.

En otro caso similar, en Ica, convocaron al pueblo a una junta para que decidiera si querían independizarse del gobierno español. Para demostrarles la buena predisposición que tenían hacia ellos, San Martín les comunicó: "Entre tanto para que conozcan cuanto es el interes con que miro a su suerte va a salir el teniente/coronel Bermudez con el armamento y demas articulos de guerra que indique a vuestra señoria en oficio de ayer...". ${ }^{18}$

La estrategia del Ejército Libertador claramente tuvo en cuenta que la primera preocupación de los pueblos era la seguridad de las personas y los bienes. Por ese motivo, a menudo ofrecieron un servicio a cambio de la devoción a la causa. Por ejemplo, en una nota el gobernador De Paula Otero le refería a su comandante Francisco Hurtado:

... remito a ud, 300 pesos para que socorra a la gente que ha de quedar con ud. Y los gastos de velas y otros gastos que ocurran facultando a ud. para que proporcione cuantos auxilios le dicte su prudencia a fin de tener a la gente contenta. Haga ud, que el pueblo jure la independencia de la America. Y que elijan un alcalde mayor al que librara ud. titulo provisional y me dara cuenta. ${ }^{19}$

18 Carta de San Martín al gobernador de Ica Juan José Salas, 17/10/1820 (CDIP, t. V, v.. 1, doc. 36, pp. 73-74).

19 Oficio de Francisco de Paula Otero a Francisco Hurtado, 17/12/1820 (CDIP, t. V, v. 1, doc.115, p. 150). 
En todos los casos se solicitaba que el pueblo se reuniera y jurara la independencia, pero también se les permitía que ellos mismos designaran una autoridad y les enviaban los auxilios monetarios y de armas. Asimismo, también les hacían promesas concretas, como en el caso de los pueblos de Acobamba, Palca, Tapo y Huasaguasi, a los cuales se les envió una circular en la que se les instaba a apoyar a los patriotas en un próximo enfrentamiento con los españoles:

... para acabar del todo con el enemigo y afirmar para siempre nuestra libertad, la seguridad de nuestras vidas y propiedades y las de todos nuestros hermanos peruanos que es a lo que aspira y procura nuestro gobernador intendente, que os asegura bajo su palabra de honor conseguira la libertad de todos los prisioneros de ese pueblo que se hallan en Lima... ${ }^{20}$

En ese caso, además de las promesas generales de seguridad, había algo más concreto, les prometían liberar a quienes habían sido tomados prisioneros por los españoles. Ese fue un tema importante durante toda la guerra porque el trato recibido por parte de ambos ejércitos era una variable crítica en el ánimo de los pueblos. La escasez de hombres y la alta tasa de deserción hacían que fuera muy común la leva obligatoria y ese tipo de presiones comprometían la fidelidad de los pueblos a cada ejército (Rabinovich, 2011). De hecho, el ejército realista impuso graves castigos a los pueblos que habían acogido a los patriotas y no les habían presentado batalla. Ese tipo de escarmiento, según refiere un testigo citado por Paz Soldán (1868, p. 48) incluía "sangre, incendios, encarnizamiento, destrucción, ruina, asesinatos, profanación, muerte (...) pueblos saqueados, campos asolados, poblaciones abrazadas, familias errantes...”. Aunque esas represalias fueron utilizadas frecuentemente para disuadir a los pueblos de apo-

20 Circular enviada a los pueblos de Acobamba, Palca, Tapo y Huasaguasi, 13/12/1820 (CDIP, t. V, v. 1, doc. 89, p. 128). 
yar a los patriotas, a menudo provocaron el efecto contrario. Ese fue el caso de los morochucos de Cangallo, cuyo pueblo fue totalmente arrasado, a pesar de lo cual apoyaron a los patriotas (Igue Tamaki, 2008, p. 70). Dado que ese tipo de acciones podía provocar el efecto contrario, el ejército realista intentó equilibrar las represalias con una prédica más mesurada. Por ejemplo, la ciudad de Caraz ya había provisto al ejército realista con 200 hombres levados a la fuerza, lo cual había generado malestar en la población de la ciudad. Ante la situación, un oficio señalaba que "sería conbeniente hacerles ver que ya sus obligaciones no son otras que defender sus territorios para afirmarlos en la justa defensa que deben hacer". ${ }^{21}$ Los generales del ejército realista se daban cuenta de que apelar a la defensa de sus territorios era lo único que podía convencer a los pueblos de enviar hombres a la guerra. Imponiéndoles por la fuerza su participación "ha disgustado a esta gente y el recelo de que se extraiga mas puede inquietar su fidelidad", por lo que la estrategia más adecuada debía ser convencerlos de incorporarse al ejército para defender su ciudad. Ya la defensa del rey no parecía un argumento lo suficientemente atractivo como para instar a la gente a apoyar al ejército realista y eso es un claro indicador de la crisis de legitimidad que padecía el gobierno virreinal en esa coyuntura.

A los líderes del Ejército Libertador también se les hacía difícil controlar la nueva situación política que habían impuesto con su presencia. A menudo, les costaba controlar las guerrillas que habían surgido por todas partes, incluidos algunos grupos de bandoleros que se hacían llamar "de la patria". Ese fue el caso de un grupo de ladrones que asolaban los caminos y haciendas de Guachipa a mediados de 1821 y anunciaban que lo hacían en nombre de la patria, aunque no tenían nin-

21 Oficio de Melchor Gutiérrez a Josef González de la Prada 26/08/1820 (CDIP, t. V, v. 1, doc. 26, pp. 58-59). 
guna conexión con el Ejército Libertador. ${ }^{22}$ También a los patriotas les resultaba complicado lidiar con las autoridades locales porque estas a menudo tomaban iniciativas propias, que no solo no tenían nada que ver con el curso de la guerra, sino que muchas veces iban en contra de los planes del Ejército Libertador. En un oficio de Álvarez de Arenales a Francisco de Paula Otero, este le comenta:

... acabo de tener noticias que don Antonio Acuña, eregido en comandante (no se por quien), se ha propasado a provocar a los enemigos hasta cerca de San Mateo con una gente sin disciplina, sin dirección y sin sosten formal, que mas bien se puede llamar montonera que tropa y contra las enemigas que son muy veteranas... en fin lo que conviene es que vuestra señoria a la mayor brevedad posible haga replegar aquella gente sobre los puntos de sus limites al comando precisamente de sujeto militar, juicioso y de conducta como considero al comandante don Manuel Canal y obrar en todo esto con mucho pulso y firmeza, para no esponer nuestro actual muy ventajoso estado. ${ }^{23}$

Mientras los realistas habían preferido la leva de los pueblos a la organización de guerrillas, los patriotas habían animado a los pueblos a organizar sus partidas de guerrillas (Igue Tamaki, 2008, p. 56). La organización de guerrillas era importante para la logística del Ejército Libertador porque estas podían cumplir tareas acotadas, como tener una línea de defensa en cada pueblo para mantener al ejército realista a distancia. También se les encomendaba funciones de control y vigilancia de los caminos de acceso a los pueblos para capturar desertores y evitar saqueos. Por último, se les pedía "proporcionar a las tropas del estado todo quanto fuese conduncente" a la par de encargarles

22 Oficio de Isidoro Villar a José de San Martin 01/06/1821 (CDIP, t. V, v. 1, doc. 280, pp. 302-303).

23 Oficio de Álvarez de Arenales a Francisco de Paula Otero, Canta, 20/12/1820 (CDIP, t. V, v. 1, doc. 119, p. 154). 
el transporte de la correspondencia. ${ }^{24}$ En ese sentido, resulta evidente que la labor cumplida por las guerrillas era vital para los ejércitos regulares, ya que sin el apoyo logístico que les brindaban (espías, acopiadores de ganado y víveres, chasquis, vanguardia defensiva) era imposible pensar en ganar la guerra. El expediente de servicios de Valentín Munarriz, guerrillero de la zona de Tambo en Huamanga, ejemplifica el carácter de nexo vital de ciertos hombres que eran comisionados por los ejércitos (en ese caso el Libertador) para que desempeñaran una variedad de tareas que eran fundamentales para el sostenimiento de la empresa militar. ${ }^{25}$

Es en este punto donde entendemos que la actividad guerrillera adquiere una dimensión política. La actividad desplegada por la guerrilla no era simplemente un acompañamiento pasivo de las acciones bélicas efectuadas por los ejércitos. No se limitaban a obedecer órdenes, ni tampoco eran simples escoltas de los ejércitos regulares, sino que representaban poderes autónomos que tenían como principal objetivo la defensa de sus territorios. Los vaivenes de la guerra hicieron que la sierra fuera alternativamente ocupada por los patriotas, luego por los realistas y de nuevo por los patriotas (Fonseca Ariza, 2010). Eso produjo una particular situación, en la cual los pueblos se hallaban en medio de una disputa de poderes en la que no había una única autoridad y su alternativa más viable era la defensa de la propiedad y el mantenimiento del orden público. Una carta de la esposa de Francisco de Paula Otero a este ejemplifica esa particular coyuntura. A partir de un hecho aislado, en el que unos libertos habían herido a un mestizo, se corrió la voz de que los negros se habían sublevado, a lo que inmediatamente hubo quienes quisieron ir a buscar a los realistas (que se acercaban a la ciudad):

24 Un ejemplo se encuentra en Jacinto del Risco a Toribio Dávalos 09/10/1821 (CDIP, t. V, v. 1, doc. 379, p. 391).

25 AGN Lima, sección colonial, Donación Misceláneas, D.10, 2-21, 129 fs., 1820-1839. 
... desde aquel momento se proclamó ya al rey con tanta imprudencia que porque un cholo al quien vive contesto la patria, lo mataron de un balazo a media noche, al dia siguiente todos clamaron para que se tomasen las medidas convenientes a la seguridad y orden de la villa (...) resolvieron pasar a Jauja a pedir al señor Ricafort remitiese cuanto antes la avanzada para contener los desordenes de los patriotas... se formaron patrullas de a pie ya caballo... a las siete de la noche llegaron los parlamentarios... trajeron el indulto... (y contaron que) el lunes entro Ricafort en Jauja con sola su caballería y encontró la población sola y todas las casas cerradas. Llamaron al cura... y el y los europeos fueron los únicos que le prestaron algún auxilio. Se publico el indulto y sin embargo nadie se presento y se mantuvo la poblacion sola hasta la noche y mañana del martes en que salio Ricafort con la caballeria, yendose con el todos los europeos y aun sus mujeres. Ese manejo de los jaujinos irrito a Ricafort en tanta manera que dijo que a no estar empeńada su palabra por el indulto publicado reduciria a cenizas la población.?

Esta fuente permite ver la disparidad de reacciones en dos pueblos diferentes. Por un lado, Tarma, que había recibido a los patriotas con los brazos abiertos, luego de que estos se hubieran retirado camino a Lima, ante un conflicto menor inmediatamente recurrió a los realistas. Por otro lado, Jauja, un pueblo que a pesar de la ofrenda de indulto de los españoles, se mostró poco proclive a apoyar a los realistas. El indulto con el cual los espańoles perdonaban a quienes hubieran colaborado con los patriotas a cambio de que se sumaran a las filas realistas fue ampliamente utilizado, a pesar de lo cual no siempre dio el resultado deseado. Aun así, Jauja fue más adelante base de operaciones de los realistas, pese a la desconfianza inicial que muestra la carta.

\section{Cádiz y la revolución territorial de los pueblos}

Con una situación económica apremiada por los gastos militares, un descontento social que se hacía evidente en las sucesivas rebeliones, el bandolerismo acuciante y la imposibilidad 
de eliminar a las guerrillas altoperuanas, a la Corona solo le faltaba la invasión del Ejército Libertador para ver desmoronarse lenta pero sostenidamente los cimientos políticos y militares de su dominación. Ese desmoronamiento se vio favorecido por la promulgación y aplicación de la Constitución de Cádiz (Glave, 2008). Las ideas de Cádiz, aunque solo perduraron durante un breve período entre 1812 y 1814 (y nuevamente en 1820), produjeron un impacto significativo al modificar las bases jurídicas del poder político e introducir -entre otros cambios- la abolición del tributo indígena y la posibilidad de participar en los procesos electorales a todos los que declarasen una ocupación y un domicilio estables. La difusión que tuvo la constitución en los sectores plebeyos ya ha sido comprobada en el contexto de 1812, pero no se ha tenido en cuenta su impacto en los ańos posteriores (Chiaramonti, 2005; Núñez, 2005). No solo sus alcances no fueron olvidados, sino que, por el contrario, fueron recuperados rápidamente con la llegada del Ejército Libertador en 1820 y la reinstauración promovida desde la península en el mismo año. Una prueba de ello es que apenas se conoció la noticia de la promulgación de la constitución en 1820, ya algunas comunidades indígenas se negaron a pagar el tributo. Los propios funcionarios reales reconocieron la influencia de la constitución, aunque achacaron la rebeldía indígena a los efectos de la proclama libertadora. ${ }^{26} \mathrm{Sin}$ pretender minimizar el impacto de la llegada de San Martín al territorio peruano, parece lícito suponer que las comunidades estaban convencidas de que no debían pagar el tributo porque había leyes que así lo indicaban y podían estar seguros de ello porque en años anteriores así había sido. San Martín y sus proclamas llegaron para exacerbar nociones que habían calado hondo en las comunidades y que contribuyeron a licuar el poder político del estado virreinal. Tanto es así que en un oficio

26 AGN Lima, Sección colonial. Superior Gobierno, L.91, C. 750, 1820. 
del subdelegado de Caravaya al gobernador intendente en octubre de 1820, este le comenta sobre lo que ha oído decir en su jurisdicción:

que algunos peninsulares por mandarlo todo han creado una junta de gobierno que desautoriza al monarca: Que la América debe de fundar otra sin sujecion a áquella: Que la constitucion que esperan por instantes los autoriza para sujetar a los Gefes del poder de esclavitud con que mas de 300 años se les ha tratado... la constitucion opinan que ganara mas acciones que cuantas han dado los Exercitos del Soberano en la América... Los Indios publicamente dicen que los mistis por ella se lebantaron y los sublevaron; que ahora que buelbe les ha de suceder lo mismo y crea VS. que si se instala va a suceder lo que ya estan pronosticando... ${ }^{27}$

El gobierno del virrey Pezuela se vio obligado a acatar la reinstauración de la Constitución de Cádiz a finales de 1820 y esto generó una situación original: la emergencia de fenómenos similares en espacios controlados por fuerzas enemigas y que promovían principios opuestos. La aplicación de la constitución en la zona controlada por el gobierno virreinal erosionó considerablemente el poder de decisión de los gobiernos regionales y trasladó todo el poder de decisión a los gobiernos municipales y comunales (Sala i Vila, 2011). De forma similar, en las zonas donde los patriotas mantuvieron su dominio (y no se aplicó la constitución) se verificó un reforzamiento de las redes de poder local, lo que constituyó una verdadera ruralización de las bases de poder, ya que se reforzaron las estructuras comunales y municipales en desmedro de las intendencias y gobernaciones (Halperin Donghi, 1994).

27 Nota de los subdelegados de Lampa y Puno, dan cuenta de la acción de insurgentes en esos pueblos, 24/10/1820 (CDIP, t. V, v. 1, doc. 38, pp. 76-79). 
Aquí, se produjo también, como en el virreinato de Nueva España, una "revolución territorial de los pueblos" tomando la conocida expresión de Antonio Annino (1995). Como señala Chiaramonti (2005, pp. 108-109), la creación de las municipalidades abrió un frente mucho más conflictivo y difícil de controlar que la guerra misma, pero esa circunstancia debieron soportarla ambos bandos. Un expediente de 1822, una causa promovida contra vecinos del pueblo de Huacho por parte del gobierno patriota, ilustra las particulares circunstancias que adquirió la guerra de Independencia en el Perú y el grado de autonomía que alcanzaron los poderes locales frente a los regionales. ${ }^{28}$ Los vecinos de Huacho, quienes se hallaban enfrentados con el anterior alcalde de naturales Baltasar la Rosa promovieron una causa en su contra. Habiendo conseguido una orden judicial para su detención se reunió el cabildo junto a:

... una turbamulta de peruanos que convocados todos se agolparon a la vera del despacho (de la fiscalía departamental de la costa) conminando [a la autoridad regional] a que remitiese a Lima con un par de grillos al capitán Baltasar de la rosa...

Lo interesante del expediente es lo que los vecinos alegaron como justificativo de sus actos. Ellos entendían que la autoridad regional debía ejecutar la orden judicial inmediatamente y "... que si VS asi no lo verificaba ellos de oficio lo harian porque el pueblo era el que mandaba y que como en Lima habían quitado a Monteagudo, ellos que representaban al 184 pueblo de Huacho quitarian a La Rosa”.

La referencia a Monteagudo se relacionaba con la asonada que protagonizara la ciudad de Lima para deponer a Monteagudo como ministro de gobierno de San Martín (McEvoy,

28 AGN Lima, sección colonial. Superior Gobierno, leg. 38, C. 1387, 1822, 28 Fs. 
2006; Mera Ávalos, 2005). Esos vecinos amenazaban con seguir un ejemplo que a su criterio constituía jurisprudencia. A tanto llegó la conmoción que el oficial manifestaba:

... hasta el extremo de haberme precisado a amonestarlos del modo mas serio, y prorrumpiesen algunos de los que componen el cabildo, arguyendome que todo estaba en sus alcanzes y que ellos habían de decidir todas las cosas que para eso estaba ahi el cabildo...

El expediente fue promovido en contra de quienes se consideró los instigadores de la asonada, vecinos que ostentaban algún cargo en la estructura de poder local. Si bien estos terminaron absueltos, el Ejército Libertador se vio involucrado en una disputa de poderes netamente local que amenazó con desafiar el poder político del recién creado gobierno regional. Los vecinos reunidos en el cabildo se consideraban con la autoridad suficiente para sentar justicia “... elevándose a la clase de una soberanía imaginaria, para disponer a su arbitrio de cosas pertenecientes a aquel gobierno". Esto es lo que consideraba Baltasar la Rosa, el objeto del disgusto popular y el principal instigador de la causa contra los vecinos, a quienes acusaba de haber sido partidarios de los realistas. Sin embargo, si había entre los vecinos quienes habían apoyado a los españoles en el pasado reciente, esa misma acusación le cabía al propio Baltasar la Rosa, quien en una carta fechada el 20 de septiembre de 1820 ofrecía sus servicios "con todos mis parientes y amigos de cuia lealtad estoy cerciorado hasta la evidencia" al ejército realista para la defensa "(d)el suelo español de Pisco (que) se halla profanado por unos bastardos execrables cuyo nombre detesto" ${ }^{29} \mathrm{Al}$ final, nadie estaba habilitado para tirar la primera piedra y por ese motivo todos fueron absueltos. Sin embargo, la declaración de uno de los

29 Nota de Baltasar La Rosa a Agustín Otermín ofreciendo sus servicios a los realistas, Huacho, 20/09/1820 (CDIP, t. V, v. 1, doc. 30, p. 67). 
vecinos de Huacho volvió a poner de manifiesto la penetración que habían alcanzado las ideas liberales y el uso que le daban los pueblos a fin de obtener políticas favorables a sus intereses:

“...no faltaria a los deberes de un hombre honrado y seria indigno de existir como ciudadano en una republica libre sino pidiese el ser juzgado con todo el rigor de las leyes, dandoseme la respectiva audiencia, especialmente quando hemos jurado que ante esta todos son iguales..." ${ }^{30}$

$Y$ es que, en un contexto de extremo desconcierto, los pueblos, ciudades y comunidades tomaron en sus manos la defensa de sus intereses utilizando para ello el lenguaje que Cádiz había instalado algunos años antes y que San Martín y el propio gobierno virreinal habían reflotado. Los pueblos apelaban al nuevo marco jurídico para resolver disputas internas que ponían en entredicho la autoridad del gobierno virreinal y limitaban su influencia concreta. El caso de los vecinos del pueblo de Sayán es otro ejemplo de disputas internas entre diferentes niveles dentro del gobierno local, que ponían en aprietos a la autoridad central. En ese caso, los vecinos apelaron directamente a San Martín para que este ordenara la remoción del teniente gobernador Juan Delgado por los atropellos cometidos contra el pueblo y el gobierno patriota. ${ }^{31}$ Aquí también los vecinos se congregaron en el cabildo para elevar este petitorio en el cual señalaban que:

... nuestra suerte toca los extremos de la desesperacion aumentandose nuestros males al ver que los mismos medios adoptados por V. E. para nuestro remedio se convierten en nuestro mayor daño por no cumplirse sus superiores mandatos... justicia Señor

30 AGN Lima, sección colonial. Superior Gobierno, Leg. 38, C. 1387, 1822, 28 Fs.

31 AGN Lima, sección republicana. RPJ Causas criminales, leg. 722, 1822. 
Exmo pedimos justicia que restablezca el orden, que haga sentir el imperio de las leyes y los beneficos influxos de un gobierno liberal, justicia que haga respetar la dignidad del hombre y que sirva de escarmiento a los que abusando del sagrado de la magistratura introducen la discordia y la revolucion en los pueblos...

Los vecinos denunciaban que los excesos cometidos por Delgado no permitían que se cumplieran los mandatos del nuevo gobierno. De hecho, denunciaban prácticas que los lideres del Ejército Libertador difícilmente podían tolerar. Gerónimo Pacheco, un vecino declaraba:

... que le consta por haber ido en auxilio con el subteniente don Antonio Caballero cuando este sorprendio a un esclavo que era de Ilario Bojorques, desertor del exercito y cuando en este caso el tal Ilario se expreso que don Juan Delgado se lo había permitido ofreciendole desentenderse en las ordenes que en contra de ese desertor viniesen a virtud de doce pesos que había percibido Delgado en gratificacion...

Dado que Delgado se interponía en la ejecución de los planes que el ejército tenía para la región, era necesaria una intervención, en particular porque agitaban el fantasma de la revolución social tan temido por uno y otro bando.

\section{Conclusiones}

En un contexto de alta movilización social, los sectores plebeyos participaron de la guerra de Independencia privilegiando intereses inmediatos y locales. En diferentes momentos, dependiendo de las circunstancias, tendieron a apoyar y promover proyectos políticos de corto plazo que ofrecían resultados concretos e inmediatos. A veces, estos coincidieron con los intereses del ejército realista y a veces lo hicieron con los del Ejército Libertador. Eso no significa que no apoyaran la independencia del Perú, más bien impulsaron acciones que buscaban modificar su vínculo con la autoridad existente, ya 
fuera de uno u otro bando. Lo hicieron apremiados por una coyuntura cambiante, pero también atentos a las oportunidades que esa coyuntura ofrecía de reacomodo dentro de la estructura de poder político local y regional. En ese sentido, la guerrilla fue una clara expresión de la voluntad local, tanto de los nuevos liderazgos que emergieron como de la oportunidad de establecer una nueva forma de hacer política. En ese contexto, la influencia de la Constitución de Cádiz es innegable, no solo en el lenguaje utilizado, sino también en las prácticas que auspició y posibilitó en un contexto de guerra. El resultado fue el surgimiento de una nueva cultura política en la que se mezclaron nociones del Antiguo Régimen con otras republicanas. La contracara de ese fenómeno fue la definitiva declinación de las bases de poder del Estado virreinal, que no sobrevivieron al cuestionamiento de su legitimidad política y colapsó a fines de 1824 .

Recibido: 11 de octubre del 2020

Aprobado: 20 de abril del 2021

\section{Referencias bibliográficas}

Adanaqué Velásquez, R.

(2010) Cerro de Pasco en el proceso de la independencia (1819-1824). Investigaciones sociales, 14(25), 105140.

Aldana Rivera, S.

188 (1997) Un norte diferente para la independencia peruana. Revista de Indias, LVII(209).

Anna, T. (2003)

La caída del gobierno español en el Perú. El dilema de la independencia. Lima: IEP. 
Annino, A.

(1995) Cádiz y la revolución territorial de los pueblos mexicanos, 1812-1821. En Historia de las elecciones en Iberoamérica, siglo XIX. Buenos Aires: Fondo de Cultura Económica.

Bazán Díaz, M.

(2017) La participación de los sectores populares en la rebelión de Huánuco, 1812: saqueadores, seductores e incanistas (Tesis para optar el grado de maestría). Universidad Nacional Mayor de San Marcos, Lima.

Beltrán Gallardo, E.

(1977) Las guerrillas de Yauyos en la emancipación del Perú, 1820-1824. Lima.

Bonilla, $\mathrm{H}$.

(1972) La independencia en el Perú. Lima: IEP, Eds. Campodónico. Colección Perú Problema, N. ${ }^{\circ} 7$.

Cáceres-Olazo Monroy, J. M.

(1999) Los campesinos del altiplano Q'ollavino en los movimientos contra el orden colonial hispánico (18001826). Lima: Universidad Federico Villareal. Cuadernos de Investigación, Serie Antropología, N. ${ }^{\circ}$.

Cahill, D., O 'Phelan, S.

(1992) Forging their own History: Indian Insurgency in the Southern Peruvian Sierra, 1815. Bulletin of Latin American Research, II(2), 140-161.

Chiaramonti, G.

(2005) Ciudadanía y representación en el Perú (1808-1860). Los itinerarios de la soberanía. Lima: Universidad Nacional Mayor de San Marcos, SEPS, ONPE.

Demélas, M.D.

(2007) Nacimiento de la guerra de guerrilla. El diario de José Santos Vargas (1814-1825). Lima: IFEA. 
Di Meglio, G.

(2006) ¡Viva el bajo pueblo! La plebe urbana de Buenos Aires y la politica entre la Revolución de Mayo y el rosismo. Buenos Aires: Prometeo Libros.

Echeverri, $M$. (2016)

Indian and Slave Royalists in the Age of Revolution: Reform, Revolution, and Royalism in the Northern Andes, 1780-1825. New York: Cambridge University Press.

Fisher, J.

(2000) El Perú borbónico. Lima: IEP.

Flores Galindo, A.

(1984) La ciudad sumergida. Aristocracia y plebe en Lima, 1760- 1820. Lima: Ed. Horizonte.

Fonseca Ariza, J.

(2010) ¿Bandoleros o patriotas? Las guerrillas y la dinámica popular en la independencia del Perú. Histórica XXXIV(1).

Fradkin, R.

(2006) La historia de una montonera. Bandolerismo y caudillismo en Buenos Aires, 1826. Buenos Aires: Siglo XXI Eds.

Garrett, D. T.

(2009)

Sombras del imperio. La nobleza indigena del Cuzco 1750-1825. Lima: IEP.

Glave, L. M.

(2008)

Cultura política, participación indígena y redes de comunicación en la crisis colonial. El virreinato peruano 1809-1814. Historia Mexicana, LVIII (1).

Guardino, P.

Las guerrillas y la independencia peruana, un ensayo de interpretación. Pasado y Presente (2-3), 101-117. 
Halperín Donghi, T.

(1994) Revolución y guerra. Formación de una elite dirigente en la argentina criolla. Buenos Aires: Siglo XXI Eds.

Hernández García, E.

(2008) La elite piurana y la independencia del Perú. La lucha por la continuidad de la naciente república (17501824). Lima: PUCP, Instituto Riva- Agüero.

Hünefeldt, C.

(1979) Cimarrones, bandoleros y milicianos: 1821. Históri$c a, \operatorname{III}(2)$.

Hünefeldt, C.

Lucha por la tierra y protesta indígena. Las comunidades indigenas del Perú entre colonia y republica, 18001830, Bonn: Bonner Amerikanische Studien.

Igue Tamaki, J. L.

(2008) Bandolerismo, patriotismo y etnicidad poscolonial: los 'morochucos' de Cangallo, Ayacucho en las guerras de independencia, 1814-1824 (Tesis para optar el grado de licenciado en historia). Pontificia Universidad Católica del Perú, Departamento de Historia, Lima.

Klassen, D.

(2016) The Unraveling Colonial Order: Tribute and Indigenous Politics in the Southern Peruvian Andes from the Tupac Amaru Rebellion to Independence (1781-1824) (Tesis para optar el grado de doctor). New York University, New York.

León, L.

(2011)

Ni patriotas ni realistas. El bajo pueblo durante la independencia de Chile, 1810-1822. Santiago: Centro de Investigaciones Diego Barros Arana.

Lynch, J.

(1980) Las revoluciones hispanoamericanas. Barcelona: Ariel. 
Mamani Siñani, R.

(2010) La división de los valles: Estructura militar, social y étnica de la guerrilla de La Paz y Cochabamba (18141817). La Paz: Instituto de Estudios Bolivianos.

Maqque, $\mathrm{V}$.

(2015) On Behalf of Our Community: Base of Political Culture in Late Colonial Altiplano. Antropologia Andina Muhunchik-Jathasa, 2(2).

Mata, S.

(2008) Los gauchos de Güemes. Buenos Aires: Sudamericana.

McEvoy, C.

(2006) De la comunidad retórica al Estado-nación: Bernardo Monteagudo y los dilemas del republicanismo en "América del Sud", 1811-1822. En J. Nun y A. Grimson (Comps.). Convivencia y buen gobierno. Nación, nacionalismo y democracia en América Latina. Buenos Aires: Edhasa.

Mendoza Villanueva, P.

(2012) Pasco en la guerra de la independencia. Lima: Fondo Ed. Industrias Nieto.

Mera Ávalos, A.

(2005) Cuando la patria llegó a la capital: el miedo ante el advenimiento de la independencia, 1820-1821. En C. Rosas Lauro (Ed.), El miedo en el Perú, Siglos XVI al XX. Lima: Fondo Ed. PUCP, Seminario Interdisciplinario de Estudios Andinos.

Núñez, F.

(2005) La participación electoral indígena bajo la Constitución de Cádiz (1812-1814). C. Aljovín de Losada C y S. López, Historia de las elecciones en el Perú. Estudios sobre el gobierno representativo. Lima: IEP. 
O 'Phelan Godoy, S.

(1987) El mito de la independencia concedida, los programas políticos del siglo XVIII y del temprano XIX en el Perú y el Alto Perú (1780-1840). A. Flores Galindo, Independencia y revolución (1780-1840) (t. 2). Lima: Instituto Nacional de Cultura.

O 'Phelan Godoy, S.

(1988) Un siglo de rebeliones anticoloniales. Perú y Bolivia 1700-1783. Cuzco: Centro Bartolomé de las Casas.

O 'Phelan Godoy, S.

(2009) Una inclusión condicional: indios nobles, indios del común, esclavos y castas de color entre la rebelión de Túpac Amaru y la independencia. En B. Bragoni y S. Mata (Eds.), Entre la colonia y la república. Insurgencias, rebeliones y cultura politica en América del Sur. Buenos Aires: Prometeo.

Paz Soldán M. F.

(1868) Historia del Perú independiente (v. 1). Lima: Imp. de Alfonso Lemale.

Rabinovich, A.

(2011) El fenómeno de la deserción en las guerras de la revolución e independencia en el Río de la Plata 18101829. Estudios interdisciplinarios de Latinoamérica y el Caribe, 22(1), 33-56.

Rebaza, N.

(1989) Anales del departamento de la libertad en la guerra de independencia. Lima: Banco Industrial del Perú, Fondo del libro.

Rivera Serna, R.

(1958) Los guerrilleros del centro en la emancipación peruana. Lima. 
Roel Pineda V.

(1988) La independencia, Historia general del Perú, Lima:

Ed. Gráf. Labor.

Rosado Loarte, L.

(2017) Infieles al rey: el pueblo de San Bartolomé de Huacho durante el proceso de independencia, 1812-1822. En L. Rosado Loarte, G. Riveros y P. Lanas (Eds.), Narra la independencia desde tu pueblo. Lima: IEP.

Sala i Vila, N.

$Y$ se armó el tole tole. Tributo indígena y movimientos sociales en el Virreinato del Perú, 1724-1821. Huamanga: IER José María Arguedas.

Sala i Vila, N.

(2011)

El trienio liberal en el Virreinato Peruano: los ayuntamientos constitucionales de Arequipa, Cusco y Huamanga, 1820-1824. Revista de Indias, vol. LXXI(253), 693-728.

Sánchez, S.

(2011)

Norte y sur: las milicias de Arequipa y Trujillo y la construcción de las diferencias regionales en el Perú (1780-1815). En. C. Mazzeo (Ed.), Las relaciones de poder en el Perú. Estado, regiones e identidades locales, siglos XVII-XIX. Lima: PUCP.

Sánchez Jara, C.

(2010) Los sectores populares del norte chico y su participación en la independencia del Perú. En J. Menacho Carhuanca, Hacia el Bicentenario de la Independencia del Perú 2021. $1^{\circ}$ Concurso Nacional, Lima: Ministerio de Educación, OEA, PUCP.

Seiner, L.

(2001) La rebelión de Tacna de 1811. En S. O 'Phelan, S. (Comp.), La independencia del Perú: de los Borbones a Bolivar. Lima: PUCP, Instituto Riva- Agüero. 
Serulnikov, S.

(2006) Conflictos sociales e insurrección en el mundo colonial andino. El norte de Potosi en el siglo XVIII. Buenos Aires: FCE.

Serulnikov, S.

(2010) Revolución en los Andes. La era de Túpac Amaru. Buenos Aires: Sudamericana.

Soux, M. L.

(2010) El complejo proceso hacia la independencia de Charcas (1808-1826). Guerra, ciudadanía, conflictos locales y participación indigena en Oruro. Lima: Instituto Francés de Estudios Andinos.

Vergara, G.

(1973) Montoneras y guerrillas en la etapa de la emancipación del Perú, 1820-1840. Lima.

Walker, C.

(1990) Montoneros, bandoleros, malhechores. Criminalidad y política en las primeras décadas republicanas. En C. Walker y C. Aguirre (Eds.), Bandoleros, abigeos y montoneros. Criminalidad y violencia en el Perú, siglos XVIII-XX, Lima, Instituto de Apoyo Agrario, P\&P.

Walker, C.

(2004) De Túpac Amaru a Gamarra. Cuzco y la formación del Perú republicano, 1780-1840. Cuzco: Centro Bartolomé de Las Casas. 